\title{
BMJ Global Health Examining unit costs for COVID-19 case management in Kenya
}

\author{
Edwine Barasa (D) , ${ }^{1,2}$ Angela Kairu, ${ }^{1}$ Wangari Ng'ang 'a, ${ }^{3}$ Marybeth Maritim, ${ }^{4}$ \\ Vincent Were, ${ }^{1}$ Samuel Akech, ${ }^{5}$ Mercy Mwangangi ${ }^{6}$
}

To cite: Barasa E, Kairu A, Ng'ang'a W, et al. Examining unit costs for COVID-19 case management in Kenya. BMJ Global Health 2021;6:e004159. doi:10.1136/ bmjgh-2020-004159

\section{Handling editor Lei Si}

- Additional material is published online only. To view, please visit the journal online (http://dx.doi.org/10.1136/ bmjgh-2020-004159).

Received 9 October 2020 Revised 22 February 2021 Accepted 24 February 2021

Check for updates

C Author(s) (or their employer(s)) 2021. Re-use permitted under CC BY-NC. No commercial re-use. See rights and permissions. Published by BMJ.

${ }^{1}$ Health Economics Research Unit, KEMRI-Wellcome Trust Research Programme Nairobi, Nairobi, Kenya

${ }^{2}$ Center for Tropical Medicine and Global Health, Nuffield Department of Medicine, University of Oxford, Oxford, UK ${ }^{3}$ Presidential Policy and Strategy Unit, Executive Office of the President, Nairobi, Kenya ${ }^{4}$ College of Health Sciences, University of Nairobi, Nairobi, Kenya

${ }^{5}$ Health Services Unit, KEMRIWellcome Trust Research Programme Nairobi, Nairobi, Kenya

${ }^{6}$ Office of the Chief

Administrative Secretary, Kenya Ministry of Health, Nairobi, Kenya

\section{Correspondence to}

Dr Edwine Barasa;

EBarasa@kemri-wellcome.org

\section{ABSTRACT}

Introduction We estimated unit costs for COVID-19 case management for patients with asymptomatic, mild-tomoderate, severe and critical COVID-19 disease in Kenya. Methods We estimated per-day unit costs of COVID-19 case management for patients. We used a bottom-up approach to estimate full economic costs and adopted a health system perspective and patient episode of care as our time horizon. We obtained data on inputs and their quantities from data provided by three public COVID-19 treatment hospitals in Kenya and augmented this with guidelines. We obtained input prices from a recent costing survey of 20 hospitals in Kenya and from market prices for Kenya.

Results Per-day, per-patient unit costs for asymptomatic patients and patients with mild-to-moderate COVID-19 disease under home-based care are 1993.01 Kenyan shilling (KES) (US\$18.89) and 1995.17 KES (US\$18.991), respectively. When these patients are managed in an isolation centre or hospital, the same unit costs for asymptomatic patients and patients with mild-to-moderate disease are 6717.74 KES (US\$63.68) and 6719.90 KES (US\$63.70), respectively. Per-day unit costs for patients with severe COVID-19 disease managed in general hospital wards and those with critical COVID-19 disease admitted in intensive care units are 13137.07 KES (US\$124.53) and 63243.11 KES (US\$599.51).

Conclusion COVID-19 case management costs are substantial, ranging between two and four times the average claims value reported by Kenya's public health insurer. Kenya will need to mobilise substantial resources and explore service delivery adaptations that will reduce unit costs.

\section{BACKGROUND}

The WHO declared COVID-19, caused by SARS-CoV-2, a pandemic on 11 March $2020 .{ }^{1}$ The pandemic has spread to almost all countries and territories worldwide, infecting millions of individuals and causing many deaths. ${ }^{2}$ Kenya reported its first case of COVID-19 on 13 March 2020. Since then, the country has gone through two waves of the pandemic, accumulating 100323 cases and 1751 deaths as of 17 January $2021 .{ }^{3}$ Sero-surveys however reveal that population exposure to the virus is much higher than confirmed and reported cases. ${ }^{4}$

\section{Key questions}

What is already known?

- COVID-19 has spread to nearly all countries globally, infecting and killing many, and has been declared a pandemic.

- The pandemic and its control measures have substantial direct and indirect health consequences, as well as socioeconomic impacts to individuals, households and societies at large.

- While it is expected that resources are required to respond to the pandemic, data on the costs of COVID-19 interventions are scant.

- This paper estimates the unit cost of case management for COVID-19 in Kenya; such data are useful for resource mobilisation and planning, development of appropriate purchasing arrangements and to parametise cost-effectiveness models for COVID-19 interventions.

\section{What are the new findings?}

- The estimated per-day, per-patient unit costs for asymptomatic patients and patients with mild-tomoderate COVID-19 disease under home-based care are 1993.01 Kenyan shilling (KES) (US\$18.89) and 1995.17 KES (US\$18.991), respectively.

- When these patients (asymptomatic and patients with mild-to-moderate COVID-19) are managed in an isolation centre of hospital, the same unit costs for asymptomatic patients and patients with mildto-moderate disease are fourfold higher.

- The estimated per-day unit costs for patients with severe COVID-19 disease managed in general hospital wards and those with critical COVID-19 disease admitted in intensive care units are 13 137.07 KES (US\$124.53) and $63243.11 \mathrm{KES}$ (US\$599.51).

\section{What do the new findings imply?}

- COVID-19 case management costs are substantial; Kenya and other low/middle-income countries (LMICs) will need to actively mobilise both domestic and donor resources to meet these costs.

- Kenya and other LMICs may need to adapt case management guidelines to improve efficiencies and affordability without compromising quality of care.

- Kenya and other LMICs will need mechanisms to protect patients with COVID-19 from the financial burden of healthcare costs to access COVID-19 services to minimise the risk of catastrophic healthcare expenditures and impoverishment. 
To effectively respond to the pandemic, countries need to identify cost-effective interventions, plan and mobilise resources to deploy these interventions in ways that enhance health system goals that include equitable access, efficiency, quality and financial risk protection. To effectively achieve this, countries need information on the unit costs of these interventions. One such area of intervention is case management of patients who test positive for COVID-19. While most people with COVID-19 are either asymptomatic or develop only mildto-moderate disease, estimates from Asia, Europe and the USA show that approximately $15 \%$ develop severe disease that requires oxygen support and management in general hospital wards, and 5\% have critical disease, likely to require mechanical ventilation and may develop complications such as respiratory failure, acute respiratory distress syndrome, thromboembolism, sepsis and septic shock, and multiorgan failure such as cardiac and acute kidney injury. ${ }^{5-7}$ Patients with critical disease require intensive care unit care. ${ }^{6}$

Information about the unit costs for COVID-19 case management is useful in mobilising resources and planning and budgeting for this intervention by policymakers. It is also useful in formulating appropriate healthcare purchasing arrangements by informing the development of provider payment mechanisms and rates, and as estimates to parametise cost-effectiveness models to assess the value for money of COVID-19 interventions. In this paper, we present an analysis to estimate the unit costs for COVID-19 case management in Kenya. Kenya has developed case management guidelines for COVID-19 and is pondering appropriate financing mechanisms and purchasing arrangements for case management as part of its health system response to the pandemic. Evidence of case management unit costs will therefore find utility in informing these policy decisions and could be adapted and adjusted to facilitate application in other countries with similar contexts.

\section{METHODS \\ Study setting}

Kenya's healthcare system is pluralistic, with service provision provided by both public and private healthcare facilities in almost equal measure. The public healthcare delivery system is organised in to four tiers, namely community, primary care, county referral and national referral. ${ }^{8}$ The health system is financed by revenues collected by ${ }^{9}$ : (a) the government (national and county) through taxes and donor funding, (b) the National Hospital Insurance Fund (NHIF) through member contributions, (c) private health insurance companies through member contributions and (d) out-of-pocket spending by citizens at points of care. Purchasing of healthcare services is carried out through $^{10}$ : (a) supply-side subsidies to public facilities by national and county governments, for instance, the county departments of health provide line budgets to county hospitals to finance service delivery to citizens within the county; (b) the NHIF, which contracts public and private healthcare facilities in Kenya and pays them for services provided to its enrolled members; and (c) private health insurance companies that contract private healthcare facilities and pay them for service provided to their enrolled members. The Kenyan health system is dependent on donor funding and out-of-pocket payments, with the two contributing $25.6 \%$ and $29 \%$ of total health expenditure according to the most recent national health accounts. ${ }^{11}$ The health sector is underfunded with the government expenditure on health as a percentage of gross domestic product (GDP) estimated at $2.28 \%{ }^{12}$

\section{Purpose of the cost analysis}

The purpose of this cost analysis is to develop unit cost estimates for COVID-19 case management that may be used for planning and resource allocation for the COVID-19 response, and to parametise cost-effectiveness analyses of COVID-19 interventions.

\section{Intervention description}

We costed case management for COVID-19 for four clinical severities as defined by the Kenya Ministry of Health COVID-19 case management guidelines. ${ }^{13}$ These are:

- Asymptomatic patients with COVID-19.

- Patients with COVID-19 with mild-to-moderate symptoms.

- Patients with COVID-19 with severe symptoms.

- Patients with COVID-19 in critical condition.

Kenya introduced a policy for home-based care for patients with COVID-19 who are asymptomatic or have mild-to-moderate symptoms. ${ }^{14}$ This policy is intended to reduce the burden of case management by hospitals and isolation centres and reduce the costs of management. Patient eligibility criteria for home-based care are (a) laboratory-confirmed COVID-19; (b) asymptomatic patients or patients with mild-to-moderate symptoms of COVID-19; (c) absence of comorbidities and (d) access to a suitable space for home-based isolation. ${ }^{14}$ The decision to adopt home-based care for a patient is made after an assessment of the suitability of the patients' home environment by a trained healthcare worker. Patients on home-based care are required to self-isolate at home and self-report symptoms daily to a healthcare provider using a mobile phone application. ${ }^{14}$ The patients are only transferred to a hospital if they develop severe symptoms. Patients who do not qualify for home-based care receive institutional care-in a hospital or an isolation centre. In Kenya, schools and other institutions of learning such as colleges and hotels were used as isolation centres for asymptomatic patients to spare hospital capacity. We therefore costed case management for asymptomatic patients and patients with mild-to-moderate symptoms for both scenarios-home-based care and institutional care. While asymptomatic patients do not incur costs for pharmaceuticals, they incur other costs such as "hotel costs' if provided with institutional care, staff time costs 
for monitoring, personal protective equipment (PPE) costs for protection of health workers and laboratory costs for diagnosis.

According to the Kenya COVID-19 case management guidelines, patients with severe symptoms are admitted for inpatient general hospital care with the option of oxygen therapy when needed. ${ }^{13}$ Patients in critical condition are admitted to the intensive care unit (ICU) with the option for mechanical ventilation when needed. ${ }^{13}$

\section{Costing approach, perspective and time horizon}

We used an ingredients (bottom-up) approach to costing ${ }^{15-17}$ which entails the identification of relevant inputs that are used to deliver COVID-19 case management, their quantities and their monetary value. We costed the case management of patients with COVID-19 from a health system perspective and used one patient episode of care as our time horizon.

\section{Type of costs and unit costs estimated}

We estimated full economic costs which include the monetary value of inputs whether they are accompanied with financial outlays or not. ${ }^{18}$ The costs estimated as a hybrid of real-world costs and guideline costs. This was necessitated by the challenges associated with collecting data during a pandemic, where movement restrictions and other physical distancing measures precluded ideal primary data collection. We therefore obtained realworld data from three public health facilities designated as COVID-19 treatment centres and from programme staff responsible for implementing home-based care. This was augmented with information from several COVID-19 guidelines to plug data gaps. We estimated the following unit costs for (a) per patient completing treatment cost of COVID-19 case management, and (b) per-patient, perday cost of COVID-19 case management for the following patient categories and delivery strategies:

1. Asymptomatic patients with COVID-19 on home-based care.

2. Asymptomatic patients with COVID-19 on institutional care (admitted to hospitals or isolation centres).

3. Symptomatic patients with mild-to-moderate COVID-19 on home-based care.

4. Symptomatic patients with mild-to-moderate COVID-19 on institutional care (admitted to hospitals or isolation centres).

5. Patients with COVID-19 with severe symptoms admitted in hospitals.

6. Patients with COVID-19 with critical disease admitted to ICUs.

\section{Measuring resource use}

For each of the unit costs, we costed all the direct and ancillary inputs that go into the delivery of the case management. Broadly, this included health facility 'hotel costs' which included non-clinical costs of inpatient accommodation and overheads (eg, management, electricity, water, infrastructure), staff time,

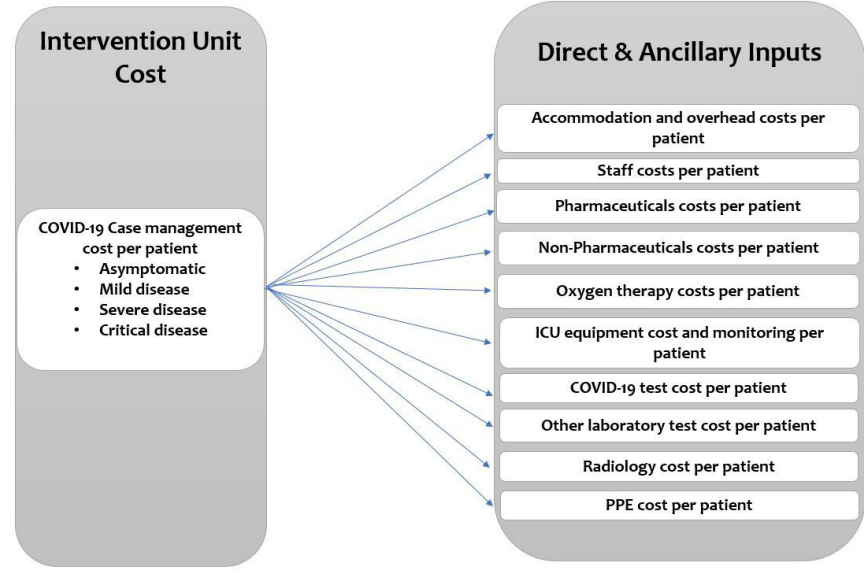

Figure 1 COVID-19 case management unit costs. ICU, intensive care unit; PPE, personal protective equipment.

pharmaceutical and non-pharmaceutical patient-level interventions, laboratory test, radiology costs and costs for PPE (figure 1).

We obtained data on inputs and their quantities from billing reports (that document on the amounts that health facilities bill the Ministry of Health to reimburse them for the costs incurred to manage patients with COVID-19) from three public health facilities designated as COVID-19 treatment centres, and the Kenya COVID-19 guidelines on (a) case management, ${ }^{13}$ (b) home-based care ${ }^{14}$ and (c) human resources requirements. ${ }^{19}$ These guidelines outlined the interventions, resources and resource quantities that ought to be used for case management of patients with COVID-19 in Kenya. The online supplemental information outlines the sources of input identities and quantities to distinguish between information obtained from real-world observation and guidelines. We obtained data on input costs from recent primary cost data whose estimates were appropriate to the COVID-19 pattern of care, primary data from three COVID-19 public treatment healthcare centres and market prices.

\section{Accommodation and overheads (hotel costs)}

We obtained per-day costs for accommodation and overheads from median costs reported in a cost analysis of 20 healthcare facilities in Kenya in 2018 (the VALUE TB Study). The VALUE TB Study combined a top-down and bottom-up approach, and a health system perspective to estimate the unit costs for tuberculosis interventions in Kenya from a sample of 20 public and private health facilities from 8 out of 47 counties in 2018. The VALUE TB Study collected data from level 3 and 4 public, private and faith-based healthcare facilities. We obtained the median of the inpatient day cost of the level 4 (county hospitals) public facilities in the sample. ${ }^{6}$ Accommodation and overhead costs include costs for non-medical inputs including accommodation, management, catering, laundry and cleaning, electricity and water. 


\section{Staffing}

We obtained data on the type of staff, and time spent on patients from reports of actual staff allocation in three public COVID-19 treatment centres and the Kenya Ministry of Health human resource guidelines for the management of COVID-19 (online supplemental file 1). The human resource guidelines for COVID-19 provide information about staff categories and staff-to-patient ratios to be used in COVID-19 treatment centres. This includes both staff involved in the direct care of patients such as medical doctors and nurses, and those involved in indirect care of patients such as pharmacists and lab staff. We computed the amount of staff time spent on a patient in a day as follows. First, we computed the total staff time (in minutes) allocated to a COVID-19 treatment centre ward by obtaining the multiple of the number of a specific cadre of staff working in that ward in one shift, the number of shifts in a day and the length of each shift in minutes. Second, we computed the amount of time allocated/spent on a patient per day in the ward by dividing the total staff time allocated to the ward by the number of patients admitted in ward, assuming full capacity, and equal allocation of time across all admitted patients. Finally, we multiplied the staff time allocated to the patient in a day in minutes by the employment cost of that cadre of staff per minute to obtain the per-day staff cost of a patient admitted in a COVID-19 treatment centre. We obtained staff costs from official public sector staff salaries data provided to us by county governments in Kenya.

\section{Pharmaceuticals and non-pharmaceuticals (fluids, oxygen, devices), and PPE}

Online supplemental file 1 outlines the list of medicines and non-pharmaceuticals that are used in the management of COVID-19 in Kenya. These were obtained from COVID-19 clinical guidelines for Kenya and billing information from three public COVID-19 treatment centres. We obtained costs for medicines, and nonpharmaceuticals from market prices reported in the 2020 Kenya drug index catalogue. ${ }^{20}$ This catalogue provides current prices of all available brands of pharmaceuticals and non-pharmaceuticals in Kenya. We used median costs of available generic medicines or brands of nonpharmaceuticals. We only used the price of originator medicines when they were the only ones available in the Kenyan market (ie, there was no generic alternative). Costs for PPE were from market prices.

We obtained the unit cost of a litre of oxygen by computing the annual costs of oxygen production by the volume of oxygen produced over this period. There are several oxygen production and distribution strategies. One approach that Kenya is using to scale up oxygen supply in public health facilities is through setting up oxygen plants in counties with the capacity to supply the oxygen needs of the public health facilities in the counties. We costed the production cost of this approach and specifically assumed a plant with capacity to produce 80 cylinders $\left(6.8 \mathrm{~m}^{2}\right)$ per day. This was based on information obtained from a firm that has been contracted by several counties in Kenya to set up and operate an oxygen plant in counties on behalf of county governments. We computed annual capital and recurrent costs of operating the oxygen plant and divided this by the annual oxygen production volumes to obtain the oxygen costs per litre. To obtain quantities of oxygen consumed, we assumed that patient with severe COVID-19 needing oxygen would need a dose of $5 \mathrm{~L} / \mathrm{min}$ while critical patients in ICU would need $15 \mathrm{~L} / \mathrm{min}$ based on Kenya Ministry of Health COVID-19 case management guidelines. We further assumed that patients with severe disease would be on oxygen for $20 \%$ of the time they are admitted while those in ICU would be on oxygen $50 \%$ of the time based on expert opinion.

\section{Laboratory and radiology costs}

Online supplemental file 1 outlines the laboratory and radiology test carried out on patients with COVID-19 in Kenya. These were obtained from COVID-19 clinical guidelines for Kenya and billing information from three public COVID-19 treatment centres. We obtained information on inputs, their quantities and costs for the PCR COVID-19 test from one of the national COVID-19 testing centres in Kenya. We used unit costs of laboratory tests and radiology by health facilities from the 2018 cost survey of 20 healthcare facilities in Kenya to represent their costs.

\section{Capital costs}

We annualised capital costs using their respective useful life years, and a $3 \%$ discount rate. Capital costs included the costs of buildings, medical equipment and motor vehicle. Details on the identities of capital inputs and their respective useful life years are provided in the online supplemental information. We obtained equipment costs from local market prices. Medical equipment was assumed to have a useful life of 5 years.

\section{Transferring costs over time}

We used GDP deflators ${ }^{21}$ for Kenya to adjust 2018 input costs to 2020 and used an exchange rate of US $\$ 1=105.49$ Kenya shillings (KES), derived from oanda.com and accessed on 30 June 2020, to convert KES to US\$. We report our findings in $2020 \mathrm{KES}$ and US\$.

\section{Sensitivity analysis}

We carried out one-way sensitivity analysis by varying staff time and PPE cost. Specifically, while the base case used actual staff ratios observed from the three hospitals, we used the staff ratios recommended by the Kenya COVID-19 human resource guidelines in the sensitivity analysis. The staff ratios prescribed by guidelines (online supplemental file) are substantially higher than what was observed in the three hospitals. Further, given that PPE costs were likely inflated, we carried a sensitivity analysis where we reduced PPE costs by $30 \%$. 
Table 1 COVID-19 case management unit costs for asymptomatic patients

\begin{tabular}{|c|c|c|c|c|c|c|}
\hline \multirow[b]{2}{*}{ Inputs } & \multicolumn{3}{|c|}{ Home-based care unit costs per case } & \multicolumn{3}{|c|}{$\begin{array}{l}\text { Hospital/isolation centre care } \\
\text { costs per case }\end{array}$} \\
\hline & KES & US\$ & $\begin{array}{l}\% \text { of total } \\
\text { cost }\end{array}$ & KES & US\$ & $\begin{array}{l}\% \text { of total } \\
\text { cost }\end{array}$ \\
\hline Health worker transport cost & 1000.00 & 9.48 & 3.27 & - & - & - \\
\hline Accommodation and overheads & - & - & - & 22829.61 & 216.41 & 28.32 \\
\hline Staffing & 2243.43 & 21.27 & 7.35 & 14279.78 & 135.36 & 17.71 \\
\hline Pharmaceuticals (medicines, etc) & - & - & 0.00 & - & - & - \\
\hline Non-pharmaceuticals (fluids, devices, etc) & - & - & 0.00 & - & - & - \\
\hline COVID-19 test & 1816.62 & 17.22 & 6.75 & 1816.62 & 17.22 & 2.25 \\
\hline Other laboratory tests & 0 & 0 & 0.00 & 0 & 0.00 & 0.00 \\
\hline Radiology & 0 & 0 & 0 & 0 & 0 & 0 \\
\hline Personal protective equipment & 18856.04 & 178.74 & 70.09 & 41686.93 & 395.17 & 51.71 \\
\hline Total cost per patient & 23916.08 & 226.71 & & 80612.94 & 764.16 & \\
\hline Patient cost per day & 1993.01 & 19 & & 6717.74 & 63.68 & \\
\hline
\end{tabular}

KES, Kenyan shilling.

\section{RESULTS}

Unit costs for patients with COVID-19 who are asymptomatic and have mild-to-moderate disease

Tables 1 and 2 outline the unit costs for COVID-19 case management of patients who are asymptomatic and those who have mild-to-moderate symptoms, respectively. Perday unit costs for home-based care case management of asymptomatic patients and patients with mild-to-moderate symptoms are 1993.01 KES (US\$18.89) and 1995.17 KES (US\$18.991), respectively. When these patients are managed in a general hospital ward or an isolation centre, per-day unit costs for asymptomatic patients and patients with mild-to-moderate symptoms are estimated to be 6717.74 KES (US\$63.68) and 6719.90 KES (US\$63.70), respectively. There is a negligible cost difference in the management of asymptomatic patients and patients with mild-to-moderate disease. This is because patients with mild-to-moderate disease only incur additional costs for symptom relievers such as paracetamol. PPE accounts for the largest share of costs for asymptomatic and mild-tomoderate disease. This is because these patients receive minimal interventions. They for instance hardly receive any medicines, do not undergo any radiological tests and do not receive supplemental oxygen.

Unit costs under home-based care are substantially lower than unit costs for institutional care (hospitals or isolation centres). This is because home-based care avoids hospital accommodation and overhead costs and is characterised by minimal health worker-patient physical interactions, and hence saves on staffing,

Table 2 COVID-19 case management unit costs for patients with mild-to-moderate symptoms

\begin{tabular}{|c|c|c|c|c|c|c|}
\hline \multirow[b]{2}{*}{ Inputs } & \multicolumn{3}{|c|}{$\begin{array}{l}\text { Home-based care unit costs per } \\
\text { case }\end{array}$} & \multicolumn{3}{|c|}{$\begin{array}{l}\text { Hospital/isolation centre care costs } \\
\text { per case }\end{array}$} \\
\hline & KES & US\$ & $\begin{array}{l}\% \text { of total } \\
\text { cost }\end{array}$ & KES & US\$ & $\begin{array}{l}\% \text { of tota } \\
\text { cost }\end{array}$ \\
\hline Health worker transport cost & 1000.00 & 9.48 & 4.18 & - & - & - \\
\hline Accommodation and overheads & - & - & - & 22829.61 & 216.41 & 28.31 \\
\hline Staffing & 2243.43 & 21.27 & 9.37 & 14279.78 & 135.36 & 17.71 \\
\hline Pharmaceuticals (medicines, etc) & 25.92 & 0.25 & 0.11 & 25.92 & 0.25 & 0.03 \\
\hline Non-pharmaceuticals (fluids, devices, etc) & - & - & - & - & - & - \\
\hline COVID-19 test & 1816.62 & 17.22 & 7.59 & 1816.62 & 17.22 & 2.25 \\
\hline Other laboratory tests & & & 0.00 & - & & 0.00 \\
\hline Radiology & - & - & - & 2961.70 & 28.08 & 1.53 \\
\hline Personal protective equipment & 18856.04 & 178.74 & 78.76 & 41686.93 & 395.17 & 51.70 \\
\hline Total cost per patient & 23942.00 & 226.96 & & 80638.86 & 764.41 & \\
\hline Patient cost per day & 1995.17 & 18.91 & & 6719.90 & 63.70 & \\
\hline
\end{tabular}

KES, Kenyan shilling. 
Table 3 COVID-19 case management unit costs for patients with severe and critical COVID-19 disease

\begin{tabular}{|c|c|c|c|c|c|c|}
\hline \multirow[b]{2}{*}{ Inputs } & \multicolumn{3}{|c|}{$\begin{array}{l}\text { Unit costs for severe COVID-19 } \\
\text { disease }\end{array}$} & \multicolumn{3}{|c|}{$\begin{array}{l}\text { Unit costs for critical COVID-19 } \\
\text { disease }\end{array}$} \\
\hline & KES & US\$ & $\begin{array}{l}\% \text { of total } \\
\text { cost }\end{array}$ & KES & USS & $\begin{array}{l}\% \text { of total } \\
\text { cost }\end{array}$ \\
\hline Accommodation and overheads & 22829.61 & 216.41 & 14.48 & 48000.00 & 455.01 & 6.32 \\
\hline Staffing & 19835.18 & 188.03 & 12.58 & 350512.56 & 3322.65 & 46.19 \\
\hline Pharmaceuticals (medicines, etc) & 55224.45 & 523.49 & 35.03 & 71946.61 & 682.01 & 9.48 \\
\hline COVID-19 test & 1816.62 & 17.22 & 1.15 & 1816.62 & 17.22 & 0.24 \\
\hline Other laboratory tests & 10817.77 & 102.55 & 6.86 & 21817.77 & 206.82 & 2.87 \\
\hline Radiology & 2961.70 & 28.08 & 1.88 & 2961.70 & 28.08 & 0.39 \\
\hline Personal protective equipment & 44292.37 & 419.86 & 28.10 & 243173.78 & 2305.14 & 32.04 \\
\hline Total cost per patient & 157644.79 & 1494.38 & & 758917.30 & 7194.07 & \\
\hline Patient cost per day & 13137.07 & 124.54 & & 63243.11 & 599.51 & \\
\hline
\end{tabular}

ICU, intensive care unit; KES, Kenyan shilling.

accommodation and PPE costs. The only costs associated with health worker interactions are transport costs to assess the patient's home for suitability of home-based care.

\section{Patients with severe and critical COVID-19 disease}

Table 3 outlines the unit cost for case management of patients with COVID-19 with severe and critical disease. Per-day unit costs for case management for severe disease are estimated to be 13 137.07 KES (US\$124.53). Per-day unit costs for case management for critical disease are estimated to be $63243.11 \mathrm{KES}$ (US\$599.51). Severe disease patient costs differ from those of hospitalised patients with mild-to-moderate disease because of additional costs for pharmaceuticals (eg, antibiotics), staff and oxygen therapy. Patients with critical disease incur higher intensive care-related costs that include specialist staff (eg, critical care physicians, anaesthetists) and more staff time per patient, pharmaceuticals (antibiotics and anaesthesia medicine) and non-pharmaceuticals (eg, total parenteral nutrition), mechanical ventilation and other monitoring equipment costs. Pharmaceuticals and PPE are the key contributors of costs for the management of patients with severe COVID-19. This is because more health workers are involved in the care of these patients (increasing PPE costs) and the patients receive pharmaceutical and nonpharmaceutical interventions such as antibiotics, fluids and oxygen. Staff costs contribute the largest share of costs for critical patients with COVID-19 because these patients not only need more numbers of staff, they also need more staff time (health worker-patient ratio) and more specialised care (such as physicians and anaesthetists) which cost more.

\section{Sensitivity analysis}

Varying staff time by using the staff ratios that are prescribed in Kenya COVID-19 human resource management guidelines does not change the cost of home-based care since the prescribed staff ratios are maintained in practice. Hospital-based care changes substantially, ranging from $24.57 \%$ for critical disease to $73.73 \%$ for asymptomatic and mild-to-moderate patients. Reducing the cost of PPE by $30 \%$ reduces the cost of care by between $8 \%$ for severe disease managed at home and $46 \%$ for critical care (table 4 ).

\section{DISCUSSION}

This study presents evidence on the costs of COVID-19 case management in Kenya. Specifically, its presents unit costs for the management of asymptomatic patients, and patients with COVID-19 with mild-to-moderate, severe and critical disease. For asymptomatic and mildto-moderate disease patients, we analyse costs for homebased care and those for care in isolation centres or general hospital wards. The findings show that COVID-19 case management costs are substantial, when compared with typical case management costs in Kenya. For instance, when compared with the average claims value $(40000$ KES) reported by Kenya's national health insurer, the NHIF, hospital management of asymptomatic and mildto-moderate COVID-19 is two times higher while that for severe disease is four times higher. These high case management costs have several implications. First, these costs will put a fiscal strain to LMIC health systems like Kenya because of existing resource challenges. Kenya will need to actively mobilise both domestic and donor resources to meet these costs. Second, Kenya and other 
Table 4 Sensitivity analysis results

\begin{tabular}{|c|c|c|c|}
\hline COVID-19 disease severity category & Base case & $\begin{array}{l}\text { Cost per patient (KES) } \\
\text { after varying staff ratios } \\
\text { ( } \% \text { difference) }\end{array}$ & $\begin{array}{l}\text { Cost per patient (KES) } \\
\text { after varying PPE cost } \\
\text { (\% difference) }\end{array}$ \\
\hline Asymptomatic disease (home-based care) & 23916.08 & $23916.08(0)$ & $18529.27(23)$ \\
\hline Asymptomatic disease (hospital care) & 80612.94 & $140069.86(73.73)$ & $68106.86(16)$ \\
\hline Mild-to-moderate disease (home-based care) & 23942.00 & $23942.00(0)$ & $13199.23(45)$ \\
\hline Mild-to-moderate disease (hospital care) & 80638.86 & 140095.78 (73.73) & $68132.78(16)$ \\
\hline Severe disease & 157644.79 & $228212.51(44.76)$ & $144357.08(8)$ \\
\hline Critical disease & 758917.30 & $945353.63(24.57)$ & $685965.17(46)$ \\
\hline
\end{tabular}

KES, Kenyan shilling; PPE, personal protective equipment.

LMICs may need to adapt case management guidelines further to improve efficiencies and affordability without compromising quality of care. A good example is the home-based care strategy that Kenya has already adopted for patients who are asymptomatic and those with mildto-moderate disease. Our findings show that unit costs for home-based care are four times lower than those for institutional care resulting in substantial cost-savings. However, not all asymptomatic and mild-to-moderate disease patients qualify for home-based care, and some will still need to be institutionalised because they are high risk (eg, have comorbidities) or their home environments are unsuitable for home-based care. These include individuals living in low-income housing including urban informal settlements. These patients will still need to be institutionalised. However, the use of the same selfreporting mobile technology could for instance minimise health worker-patient interactions and substantially reduce both staffing and PPE costs even for these hospitalised patients. Further, a lower cadre of health workers could also be used to monitor patients in isolation centres. Other adaptations could target cost drivers such as length of stay and discharge protocols, with patients discharged to home-based care as soon as their symptoms improve from severe to mild/moderate. A third implication is that Kenya and other LMICs will need mechanisms to protect patients with COVID-19 from the financial burden of healthcare costs to access COVID-19 services. If these costs are passed to patients as direct healthcare costs, they will result in substantial levels of catastrophic healthcare expenditures and impoverishment. There is therefore an urgent need for Kenya and LMICs in similar situations to develop a prepayment mechanism to provide financial risk protection to patients and households against the financial hardship that they will face if required to pay for COVID-19 case management costs out of pocket.

This analysis has several limitations. First, we extensively relied on normative guidelines assumptions and cost data from previous studies, and only collected data from three COVID-19 treatment centres because it was impossible to carry out real-world extensive data collection given existing physical distancing restrictions. However, this limitation is mitigated by the fact that there is no specific COVID-19 treatment and that COVID-19 case management reflects management of patients without COVID-19 with the same symptoms. The cost survey we relied on was also relatively recent. Second, this analysis presents data for public sector costs. Private sector costs would be useful given that the COVID-19 response will require governments to purchase services from both the public and private sectors in settings like Kenya where the private sector plays a significant role in healthcare service provision. Third, input costs for some items, especially PPE, are volatile because of market disruptions and are likely to stabilise much later, and thus reducing the unit costs of case management. We have however used market prices 8 months into the pandemic which are likely to be closer to the stable prices in the future rather than the costs at the beginning of the pandemic. Fourth, we did not analyse costs for the range of possible COVID-19 complications. This is because unit costs exist for some of these, for instance for kidney replacement therapy, and costing the entire range of possible complications would require data that were not available given the fieldwork restrictions as a result of physical distancing measures. Fifth, estimates for length of stay are obtained from a study in a different setting, rather than Kenya. Anecdotal evidence from clinicians managing COVID-19 in Kenya suggests however that the length of stay for Kenya does not vary much from the estimate we used. These limitations notwithstanding, the estimates we present will be useful in informing Kenya's resource mobilisation for the COVID-19, budgeting and planning, as well as informing the country's plan to develop appropriate purchasing mechanisms that include provider payment mechanism and rates that are appropriate for COVID-19. The estimates will also find utility in parametising costeffectiveness models for COVID-19 interventions as and when they become available such as a COVID-19 vaccine. While these cost estimates have been developed for Kenya, they could potentially find use and applicability in other LMICs with comparable settings after adapting and adjusting to country-specific assumptions.

Twitter Edwine Barasa @edwinebarasa and Samuel Akech @Sam_Akech 
Contributors EB, WN and MM conceptualised the study. EB, AK, SA and MBM collected data. $E B$ and $A K$ analysed the data. EB wrote the first draft of the manuscript. All authors contributed to subsequent revisions of the manuscript.

Funding This manuscript is published with the permission of the director of KEMRI. The work is funded by the International Decision Support Initiative (IDSI). Additional funds from a Wellcome Trust core grant awarded to the KEMRI-Wellcome Trust Research Program (\#092654) supported this work.

Disclaimer The funders had no role in study design, data analysis, decision to publish, drafting or submission of the manuscript. The views expressed in the paper are those of the authors and not of the organisations they represent.

Competing interests None declared.

Patient consent for publication Not required.

Ethics approval The KEMRI Scientific and Ethics Review Unit approved this study under KEMRI/RES/7/3/1.

Provenance and peer review Not commissioned; externally peer reviewed.

Data availability statement All data relevant to the study are included in the article or uploaded as supplemental information.

Supplemental material This content has been supplied by the author(s). It has not been vetted by BMJ Publishing Group Limited (BMJ) and may not have been peer-reviewed. Any opinions or recommendations discussed are solely those of the author(s) and are not endorsed by BMJ. BMJ disclaims all liability and responsibility arising from any reliance placed on the content. Where the content includes any translated material, BMJ does not warrant the accuracy and reliability of the translations (including but not limited to local regulations, clinical guidelines, terminology, drug names and drug dosages), and is not responsible for any error and/or omissions arising from translation and adaptation or otherwise.

Open access This is an open access article distributed in accordance with the Creative Commons Attribution Non Commercial (CC BY-NC 4.0) license, which permits others to distribute, remix, adapt, build upon this work non-commercially, and license their derivative works on different terms, provided the original work is properly cited, appropriate credit is given, any changes made indicated, and the use is non-commercial. See: http://creativecommons.org/licenses/by-nc/4.0/.

ORCID iD

Edwine Barasa http://orcid.org/0000-0001-5793-7177

\section{REFERENCES}

1 Cucinotta D, Vanelli M. WHO Declares COVID-19 a pandemic. Acta Biomed 2020;91:157-160-60.

2 WHO. Coronavirus disease 2019 (COVID-19) Situation Report - 77 [Internet]. Geneva, 2020. Available: https://www.who.int/docs/ default-source/coronaviruse/situation-reports/20200406-sitrep-77covid-19.pdf?sfvrsn=21d1e632_2
3 National Emergency Response Committee on Coronavirus. Update on COVID-19 in the country and and response measures, as at January 27, 2021, 2021.

4 Uyoga S, Adetifa IMO, Karanja HK, et al. Seroprevalence of antiSARS-CoV-2 IgG antibodies in Kenyan blood donors. Science $2021 ; 371: 79-82$.

5 WHO. Clinical management of COVID-19 [Internet]. Geneva, 2020. Available: file:///C:/Users/ebarasa/Downloads/WHO-2019-nCoVclinical-2020.5-eng.pdf

6 Baker T, Schell CO, Petersen DB, et al. Essential care of critical illness must not be forgotten in the COVID-19 pandemic. The Lancet 2020;395:1253-4. doi:10.1016/S0140-6736(20)30793-5

7 Li J, Huang DQ, Zou B, et al. Epidemiology of COVID-19: a systematic review and meta-analysis of clinical characteristics, risk factors, and outcomes.. J Med Virol [Internet] 2020 https://pubmed. ncbi.nlm.nih.gov/32790106/

8 Ministry of Health. Kenya health policy 2014-2030. Nairobi, 2011.

$9 \mathrm{MOH}$. Kenya universal health coverage policy 2020-2030. Nairobi, 2020.

10 Mbau R, Kabia E, Honda A, et al. Examining purchasing reforms towards universal health coverage by the National Hospital insurance fund in Kenya. Int J Equity Health 2020:19:1-18.

$11 \mathrm{MOH} .2017$ National health accounts. Accra, 2019.

12 Barasa E, Nguhiu P, Mclntyre D. Measuring progress towards sustainable development goal 3.8 on universal health coverage in Kenya. BMJ Glob Health 2018;3:e000904.

$13 \mathrm{MOH}$. Interim guidelines on management of COVID-19 in Kenya [Internet]. Nairobi, 2020. Available: https://www.health.go.ke/wpcontent/uploads/2020/06/Updated-Case-Management-Guidelines2603 20-1.pdf

$14 \mathrm{MOH}$. Home-based isolation and care guidelines for patients with COVID-19 [Internet]. Nairobi, 2020. Available: https://www.health.go. ke/wp-content/uploads/2020/06/Home-Based-Isolation.pdf

15 Drummond MF, Sculpher JM, Torrance WG, et al. Methods for the economic evaluation of health care programmes. Third Edit. Oxford: Oxford University Press, 2005.

16 Creese A, Parker D. Cost analysis in primary health care: a training manual for programme managers. Geneva: World Health Organization, 1994: 155

17 Johns B, Baltussen R, Hutubessy R. Programme costs in the economic evaluation of health interventions. Cost Effective Resour Alloc 2003;1:1-10.

18 Vassall A, Sweeney S, Kahn JG, et al. Reference Case for Estimating the Costs of Global Health Services and Interventions [Internet]. London;, 2017. Available: https://ghcosting.org/pages/standards/ reference_case

$19 \mathrm{MOH}$. Interim guidelines on human resource for health during COVID-19 response. Nairobi, 2020.

20 Kimotho J. East Africa drug index. 17th edn. Nairobi: Pharmaceutical Loci Publishers, 2020.

21 Walker D, Kumaranayake L. Allowing for differential timing in cost analyses: discounting and annualization. Health Policy Plan 2002:17:112-8. 